\title{
STUDY ON EFFICACY OF CONJUNCTIVAL AUTOGRAFT SURGERY WITH LIMBAL STEM CELLS IN ADVANCED, RECURRENT PTERYGIUM
}

\author{
Subbiah Vasan Chandrakumar', Sudalaiyandi Ganapathirajesh'², Shanmugasami Kavitha3 ${ }^{3}$, Sundararajalu Abirami, Mohanasundaram \\ Vijayalakshmi ${ }^{5}$, Somasundaram Vijayan', Alagarsamy Priyadharshini ${ }^{7}$
}

\begin{abstract}
${ }^{1}$ Associate Professor, Department of Ophthalmology, Madurai Medical College. ${ }^{2}$ Associate Professor, Department of Ophthalmology, Madurai Medical College. ${ }^{3}$ Senior Resident, Department of Ophthalmology, Madurai Medical College. 4Junior Resident, Department of Ophthalmology, Madurai Medical College. 5Junior Resident, Department of Ophthalmology, Madurai Medical College. 6Junior Resident, Department of Ophthalmology, Madurai Medical College. 7Junior Resident, Department of Ophthalmology, Madurai Medical College.
\end{abstract}

\section{ABSTRACT}

\section{BACKGROUND}

Pterygium is epithelial hyperplasia and elastotic degeneration of the bulbar conjunctival tissue encroaching over the cornea. Healthy limbus acts as a barrier to conjunctival overgrowth and recurrence of pterygium. Surgery is the mainstay of treatment for all types of pterygium. Despite the numerous techniques available, recurrence after surgery for pterygium presents a significant problem. Considering the importance of the limbus and its stem cells in the pathogenesis of the pterygium, a new technique has been developed that includes, in addition to the conjunctival autograft, a part of the limbal stem cells that aids in the complete anatomic and physiologic reconstruction of the excised pterygium area. This limbal reconstruction may theoretically reduce the recurre nce rate.

\section{MATERIALS AND METHODS}

A prospective observational study was conducted among 40 patients with advanced, recurrent pterygium. Only those who fulfil the inclusion and exclusion criteria were taken up for the study. After thorough pre-operative evaluation, conjunctival autograft surgery with limbal stem cells was performed in all cases of advanced, recurrent pterygium by a single surgeon. The postoperative observations were made in terms of graft oedema, graft retraction, graft necrosis, conjunctival granuloma and corneoscleral dellen. Besides above, care was taken to look for any defects in graft postoperatively by careful examination after fluorescein staining under slit lamp. The presence of any remnant fibrous tissue after excision of pterygium, proper positioning, and opposition of graft edges was also checked postoperatively. Long-term recurrence of pterygium and the best corrected visual acuity were also determined.

\section{RESULTS}

$97.5 \%$ of patients had no astigmatism postoperatively, $90 \%$ of patients had improvement in their visual acuity either with one or two lines and $2.5 \%$ of patients showed early recurrence. Mid "p" value of $<0.005$ shows there is statistical significance among preoperative and postoperative visual acuity and astigmatism with low recurrence rate after limbal conjunctival autograft surgery.

\section{CONCLUSION}

Based on the above observations, we conclude that conjunctival autograft with limbal stem cells transplantation in advanced, recurrent pterygium is a safe and effective procedure with low recurrence rate and minimal complications.

\section{KEYWORDS}

Bulbar Conjunctiva, Pterygium, Limbus Cornea.

HOW TO CITE THIS ARTICLE: Chandrakumar SV, Ganapathirajesh S, Kavitha S, et al. Study on efficacy of conjunctival autograft surgery with limbal stem cells in advanced, recurrent pterygium. J. Evolution Med. Dent. Sci. 2016;5(83):6182-6185, DOI: $10.14260 /$ jemds/2016/1397

\section{BACKGROUND \\ Pterygium is epithelial hyperplasia and elastotic} degeneration ${ }^{1}$ of bulbar conjunctival tissue encroaching over the interpalpebral cornea. Long outdoor exposure to sunlight and dust like in fishermen, paddy field workers, people living

Financial or Other, Competing Interest: None.

Submission 09-09-2016, Peer Review 05-10-2016,

Acceptance 11-10-2016, Published 15-10-2016.

Corresponding Author:

Dr. Subbiah Vasan Chandrakumar,

Eye Department OP No. 50,

Govt. Rajaji Hospital, No.1, Panagal Road,

Madurai-625020, Tamilnadu.

E-mail: eyedrck@gmail.com

DOI: $10.14260 /$ jemds/2016/1397 in tropical countries, etc. increases risk 1.5 fold, whereas having a darker skin complexion and using protective glasses substantially decreased the risk of developing pterygium. Ultraviolet (UV) light is one of the major factors implicated in the pathogenesis of pterygium, but the mechanism by which $\mathrm{UV}^{2}$ light induces this disease remains elusive. ${ }^{2}$ Pterygium has invasive characteristics including dysplastic expression, local invasiveness, and a high recurrence rate following surgical excision.

The treatment of choice of pterygium is surgical, directed towards its excision, restoration of ocular surface integrity and prevention of recurrence. Surgical techniques include bare sclera excision, excision with simple conjunctival closure, excision with the administration of antimetabolite adjuvants, excision with conjunctival autograft and excision followed by 
amniotic membrane transplantation. Conjunctival autograft with sutures or fibrin glue is widely followed as a technique for the treatment of recurrent or advanced pterygium. The complications related to conjunctival autograft transplantation includes transient graft oedema, corneoscleral dellen, graft retraction, epithelial cysts, granuloma and graft retraction. A more significant complication such as graft necrosis may occur if the graft is not properly oriented or placed on a completely avascular zone.

Recurrent pterygium ${ }^{3}$ presents a significant surgical problem. Conjunctival shortening or symblepharon caused by multiple surgeries is especially challenging. Repeated surgical intervention in the limbal area causes severe destruction of limbal barrier function. To overcome this complication, both reconstruction of limbal barrier and suppression of the subconjunctival fibrosis are required. Considering the importance of the limbus and its stem cells in the pathogenesis of the pterygium, and as healthy limbus acts as a barrier to conjunctival overgrowth, a new technique has been developed recently. In addition to the conjunctival autograft, a part of the limbal stem cells is included that aids in the complete anatomic and physiologic reconstruction of the excised pterygium area. This limbal reconstruction may reduce the recurrence rate.

A pterygial regrowth was considered as clinically significant recurrence when a surgical procedure was required to remove proliferating conjunctival tissue growing over the cornea. Three distinct morphologic recurrence patterns ${ }^{4}$ were found:

a. Regrowth Over the epithelial defect4: A completely defective epithelium on the graft can lead to aggressive fibrovascular growth, as frequently seen in bare sclera method, as the reproliferative tissue extended over the original site of the pterygium. Causes of the defect were wound dehiscence, primary graft failure, and a focal defect in the epithelial graft. Grafting of intact and healthy conjunctival epithelium acts as a tight barrier against abnormal fibrovascular proliferation and prevents the triggering of an aggressive epithelial regenerative signal. A small graft or excessive excision of surrounding conjunctiva can cause dehiscence. Dryness or irrigating solution can be toxic to the conjunctival epithelium.

b. Transformation of the autologous conjunctival graft 4 into pterygial tissue: the presence of graft haemorrhage can later lead to fibrous proliferation and vasculature from graft though the haemorrhage gets well absorbed in early postop period. Recurrence was characterised by a very thin and mild growth pattern. The re-proliferating tissue didn't grow over the previous pterygial head margin.

c. Regrowth from unexcised pterygial tissue: The remaining tissue originated from three sources - the remnant pterygial tissue around the superior or inferior border of the excision; the nasal margin of the excised pterygial tissue; and the tightly adherent pterygial tissue on the excised bed. The recurrent pterygial tissue usually adheres tightly to the surface and it cannot be easily removed.

\section{METHODOLOGY}

A prospective observational study was conducted among 40 patients with pterygium attending the outpatient department of Govt. Rajaji Hospital, Madurai. The inclusion criteria for the study was patients with advanced, recurrent pterygium in the age group 30-50 years with pterygium extending between the limbus and pupillary margin and over to the centre of cornea, patients with diminished vision due to astigmatism, due to corneal involvement or pupillary encroachment of pterygium, patients with progressive pterygium with ocular discomfort/restricted ocular motility and patients with recurrent pterygium (those who had undergone any one of pterygium surgery 1 - 2 years back and now has regrowth). Patients with ocular surface diseases, dry eyes, autoimmune disorders, history of trauma/any other ocular surgery other than for pterygium and with secondary pterygium due to chemical burns were excluded from the study. Patients with pseudo pterygium and glaucoma were also excluded from this study.

Pre-operative evaluation to look for the extent of corneal invasion, conjunctival thickness, depth of corneal involvement, vascularity and intensity of pigmentation along the apex were done. Under peribulbar anaesthesia adopting strict aseptic precautions, Conjunctival autograft surgery including limbal stem cells was done in all cases of advanced, recurrent pterygium by a single surgeon under peribulbar anaesthesia adopting strict aseptic precautions. The pterygial tissue and the subconjunctival fibrovascular tissue were subsequently removed as broadly as possible. After complete and meticulous dissection of the head of the pterygium from the cornea, the body of the pterygium was dissected and excised using conjunctival scissors. The conjunctival autograft was harvested from the supero-temporal side of the same eye including $1.0 \mathrm{~mm}$ margin of the limbal conjunctiva (Fig:1). Each graft was sutured using 10-0 nylon.

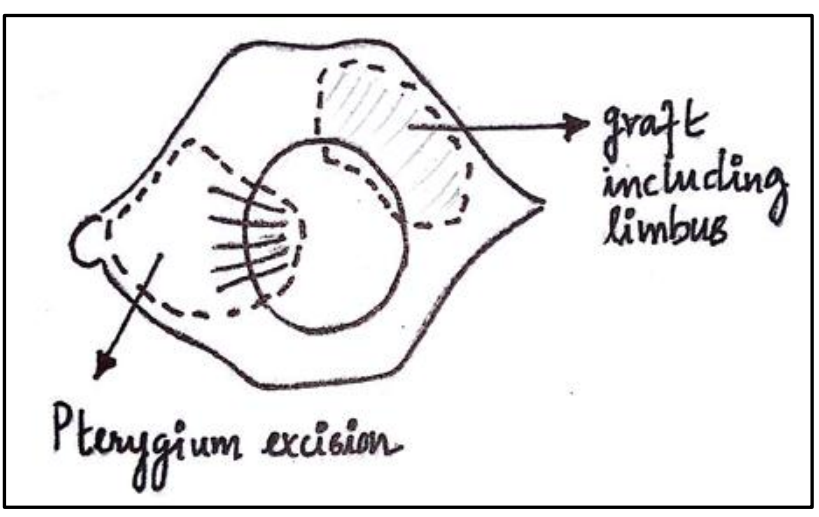

Fig. 1: Schematic Diagram showing Conjunctival Autograft including Limbal Stem Cells

Postoperative complications like graft oedema, graft retraction, graft necrosis, conjunctival granuloma and corneoscleral dellen. Care was taken to look for any defects in graft, proper positioning and apposition of graft edges, the presence of remnants or incompletely excised pterygial tissue under slit lamp postoperatively after fluorescein staining. Care was taken to check for the presence of factors contributing to recurrence. Despite the presence of contributing factors, further cases with recurrence were followed up. The best corrected visual acuity and keratometry was also determined in post-operative cases.

\section{OBSERVATION AND ANALYSIS}

In our study with 40 patients satisfying the inclusion and 
exclusion criteria, $65 \%$ of patients were males and $35 \%$ of patients were female. The increase in male patients was due to their outdoor activity and irrespective of gender, $42.5 \%$ of patients were in the age group of 41-50 years, this prevalence correlates with the available literature. Pterygium was present on the right eye in $37.5 \%$, on the left eye in $32.5 \%$ and on both eyes in $30 \%$. It is a bilateral disease, other eye develops pterygium usually by some months to years after. $90 \%$ of pterygia were present on nasal side. $7.5 \%$ of pterygia were present on temporal side and $2.5 \%$ of pterygia were present on both sides. Mostly preferred nasal location is due to more exposure of nasal side to UV radiation.

Out of 40 patients, the grades of pterygium ${ }^{5}$ were III in 32 patients (80\%), IV in 2 patients $(5 \%)$ and 6 patients $(15 \%)$ with recurrent pterygium. Current indications for surgery was ocular discomfort (57.5\%), for visual impairment $(27.5 \%)$, and among them, two persons had grade IV pterygium with pupillary axis involvement. None of the patients reported for cosmetic disfigurement. $45 \%$ of patients presented with uncorrected visual acuity (UCVA) of $6 / 36-6 / 24,25 \%$ of patients presented with UCVA of 6/18 - 6/12 (Fig: 2).

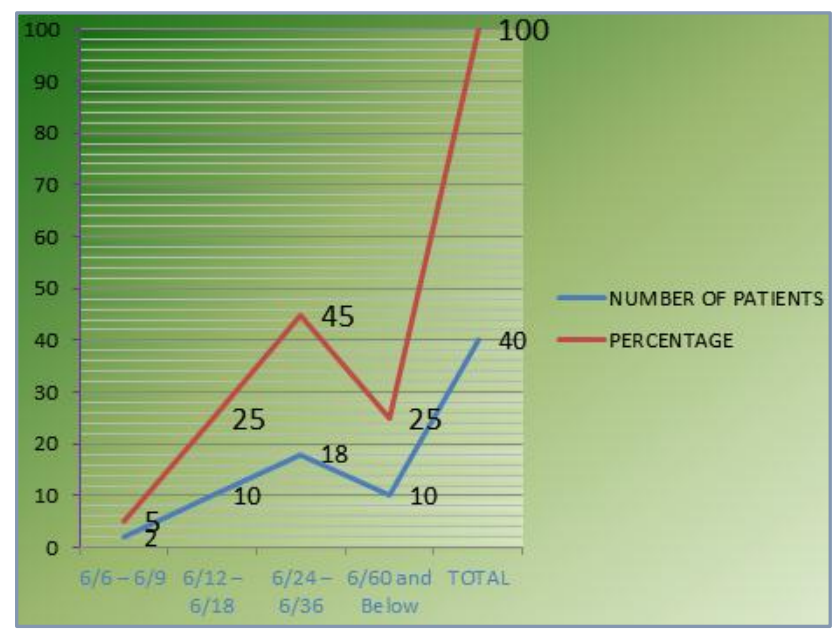

Fig. 2: 45\% of Patients Presented with UCVA of 6/36 6/24. 25\% of Patients Presented with UCVA of 6/18 -6/12. Patients with 6/60 and below also presented with Cataract changes in their natural lens

Patients with 6/60 and below also presented with cataract changes in their lens. In $95 \%$ of patients, the presence of Grade III and Grade IV pterygium or recurrent pterygium was associated with astigmatism measured by manual keratometry.

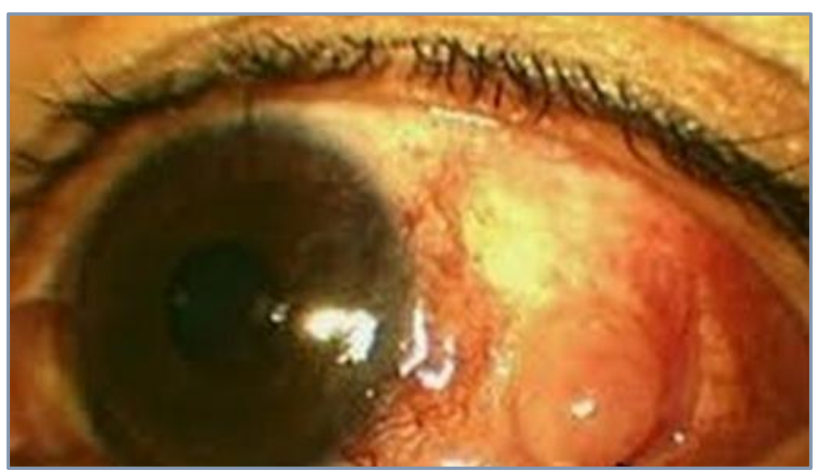

Fig. 3: Conjunctival Granuloma

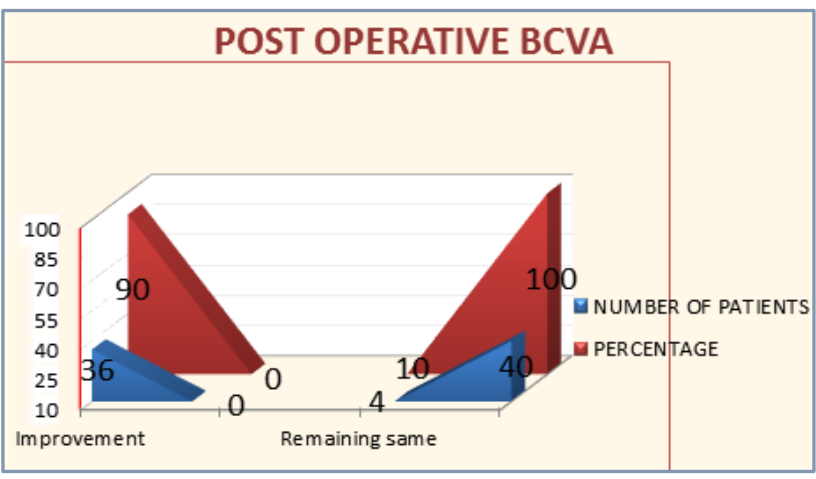

Fig. 4: Best Corrected Visual Acuity (BCVA postoperative) $90 \%$ of patients had improvement in their Visual Acuity either with one or two lines and above from Snellen's Chart

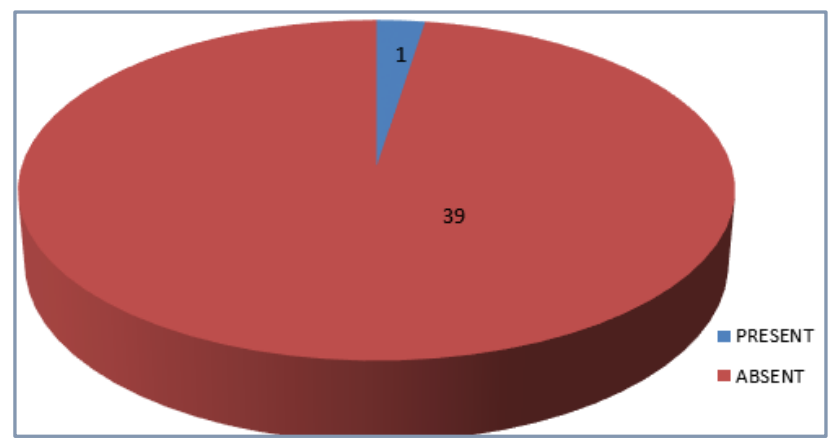

Fig. 5: Recurrence Rate: Low recurrence rate was noted in our post-operative Cases

Postoperatively, two patients presented with graft oedema on their post-operative week, graft retraction in one patient and conjunctival granuloma (Fig: 3 ) in two patients. There was no single case who developed dellen or graft necrosis. $97.5 \%$ of patients had no astigmatism postoperatively. $90 \%$ of patients had improvement in their visual acuity by one or two lines with Snellen's chart (Fig: 4). Mid 'p' value of $<0.005$ shows there is statistical significance among preoperative and postoperative visual acuity and astigmatism with a low recurrence of pterygium (Fig: 5).

There was no evidence of any limbal scar or pseudopterygium noted in the donor area in our study patients. Postoperative complications were minimal and they were managed by simple procedures. Despite being a timeconsuming procedure, based on the above observations, limbal conjunctival autograft transplantation in advanced, recurrent pterygium is a safe and effective procedure with low recurrence rate and minimal complications.

\section{DISCUSSION}

Pterygium is a worldwide conjunctival degenerative disease of multifactorial origin. Limbal cells alteration plays a major role in the aetiopathogenesis of pterygium. Despite various surgical procedures available for treatment of pterygium, recurrence remains the single and enigmatic complication for pterygium surgery.

Recurrent pterygium is difficult to treat. Radiotherapy, antimetabolites, and conjunctival limbal autograft have been proposed for treating recurrent pterygium. Antimetabolites 6 usage is sometimes associated with complications like scleral ulceration, necrosis, secondary glaucoma, corneal perforation, cataract formation, iritis and irreversibly damaged limbal 
stem cells.

Conjunctival autograft with limbal stem cells is preferred in advanced and recurrent pterygium with an idea that limbal cells act as a barrier against conjunctivalisation preventing further recurrence.

\section{CONCLUSION}

The study on the efficacy of conjunctival autograft surgery with limbal stem cells in patients with advanced, recurrent pterygium shows statistically significant results in improvement of visual acuity with a low recurrence.

\section{REFERENCES}

1. Chui J, Coroneo MT, Tat LT, et al. Ophthalmic pterygium a stem cell disorder with premalignant features. Am J Pathol 2011;178(2):817-27.
2. Nolan TM, DiGirolamo N, Sachdev NH, et al. The role of ultraviolet irradiation and heparin-binding epidermal growth factor-like growth factor in the pathogenesis of pterygium. Am J Pathol 2003;162(2):567-74.

3. Shimazaki J, Shinozaki N, Tsubota K. Transplantation of amniotic membrane and limbal autograft for patients with recurrent pterygium associated with symblepharon. $\mathrm{Br} \mathrm{J}$ Ophthalmol 1998;82:235-40.

4. Kwon SH, Kim HK. Analysis of recurrence patterns following pterygium surgery with conjunctival autografts. Medicine (Baltimore) 2015;94(4):e518.

5. Johnston SC, Williams PB, Sheppard JD. A comprehensive system for pterygium classification invest. Ophthalmol 2004;45(13).

6. Mahdy SMA, Bhatia J. Treatment of primary pterygium: role of limbal stem cells and conjunctival autograft transplantation. Oman J Ophthalmol 2009;2(1):23-6. 